\title{
Of dragon's blood and chicken bones
}

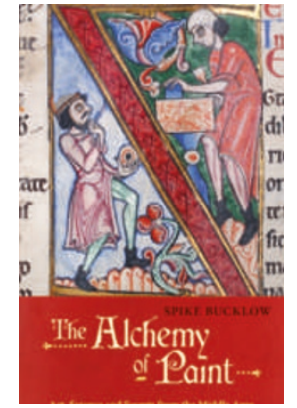

The Alchemy of

Paint: Art, Science

and Secrets from

the Middle Ages

By Spike Bucklow

MARION BOYARS

PUBLISHERS: 2009.

336PP. $€ 9.99$

Some of the traditional science in this book may have elicited a smile. If cold, that smile would be a response to the 'foolish' and 'vulgar' cloak in which deeper levels were hidden. But if warm, it could be a sign that an apparently unknown concept was actually quite familiar and had only temporarily been forgotten. Such a response is like an unexpected homecoming or release from discomfort. It is a sign of recognition and belonging, and is one of the proofs of the traditional doctrine that 'learning' is in fact only 'recollection' - the soul having drunk from the River of Forgetfulness before being born on earth.

This footnote (on page 223) in Spike Bucklow's book is an interesting, yet incomplete enumeration of the types of expressions that may develop on one's face when reading his book. As a reader with a scientific background, I didn't often feel a cold smile on my face; I was comforted by the glow of a warm smile on many occasions. During most of the time of reading, however, there was neither a cold nor a warm smile, but rather a set of furrows, friendly furrows. This is not an easy book to read. It uses terminology and associations at a dazzling tempo that creates a language closer to poetry than to prose. Such a language might be suitable for the processes and ideas around the meaning, interpretation, preparation and use of ancient colouring matters, but it requests patience and perseverance from the reader. Of course, there is no single reason why a reader should not be patient and persevering; and when she or he is, then a marvel of interesting, intriguing, challenging and funny anecdotes is waiting to be discovered.

Such anecdotes can even be discovered at the very beginning of the book where the position, use and above all misuse of colour in society are discussed. Then come the low- and high-end sources of black, picked chicken bones or tusk ivory, respectively, followed by expressing the cost of purple in kilos of cheese and litres of wine. The mention of the parallel between the role of plants in the creation of colour and in medicine in the Middle Ages is interesting because this connection still rightfully exists in present-day China.

A highlight of this book may be found in the chapter on ultramarine, where Cennini's recipe and the involvement of abstract concepts such as sympathy, desire and 'being in your element' are ably used to contrast with modern scientific concepts that led to the purification of the blue pigment from its mixture with pyrite and calcite.

An interesting extrapolation from past to present may be found in the quoted advice to buy vermilion in a clear crystallized condition, rather than as a crushed powder, to avoid the purchase of an adulterant. I guess that had I lived in Cennini's time I wouldn't have been fooled into purchasing a crushed kermes powder at an Egyptian market - in the laboratory it turned out to be a synthetic dye.

As the book progresses, Bucklow gradually tends to put more emphasis on mythological and philosophical issues that require longer reading before coming to the point that the chapter promises. This is particularly the case for the chapter on dragon's blood that discusses the topic only for a short while, and after a quarter of the chapter has already past. One exception to this tendency is the first chapter on gold, 'The riches of the unknown', which reads completely differently, displays more technical and historical issues and where legend is only briefly discussed halfway through the chapter.

Bucklow quotes alchemists with "Mercury, sulphur, the vessel, their treatment, etc., etc.; and, of course, all these things are to be understood with a grain of salt. You must understand that ... I have spoken metaphorically; if you take my words in a literal sense, you will reap no harvest ..." If you, as a reader, take this advice on board before your literary journey between myth, astrology, alchemy, mystery and a little bit of modern science, then you should not be disappointed, but rather charmed by this unusual mix of tangible and intangible issues around natural colouring matters and paint.

\section{REVIEWED BY JAN WOUTERS}

Jan Wouters is a consultant conservation scientist based in Belgium.

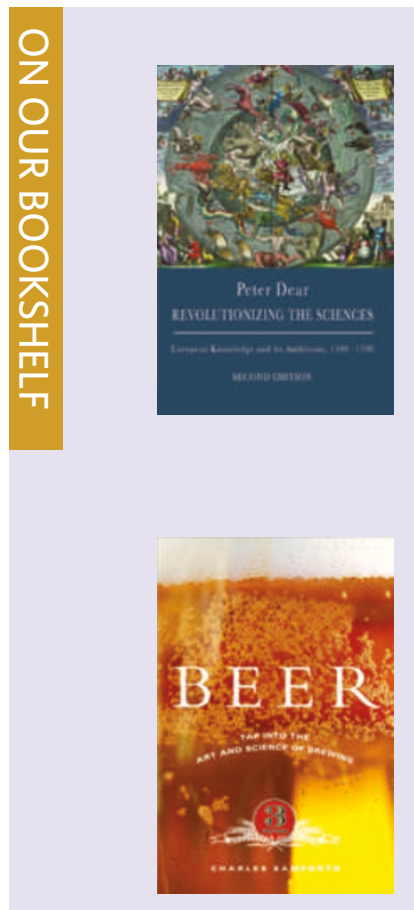

Revolutionizing the Sciences: European Knowledge and Its Ambitions, 1500-1700 by Peter Dear PRINCETON UNIV. PRESS, 2009. 216PP, \$24.95/E16.95 This is the second edition of Peter Dear's acclaimed description of the scientific revolution that occurred in Europe in the sixteenth and seventeenth centuries. The book has appeal both as a text and also to the general reader. This new edition includes extra discussion on the role of alchemy in the scientific revolution.

\section{Beer: Tap into the Art and Science of Brewing}

by Charles Bamforth

OXFORD UNIV. PRESS: 2009. 272PP. E16.99

Bamforth, Anheuser-Busch Professor of Malting and Brewing Sciences at the University of California, Davis, endeavours to educate the reader on just how much science is involved in the process of making one of the world's favourite drinks. This third edition expands the coverage of world beer styles and the development of the global brewing industry. 